\title{
Bilirubin Uridine Diphospho-glucuronyltransferase in Rat Liver Microsomes: Genetic Variation and Maturation
}

\author{
Leon Strebel and Gerard B. Odell ${ }^{[51]}$ \\ Department of Pediatrics, Johns Hopkins University School of Medicine, and the Harriet Lane Service of the \\ Children's Medical and Surgical Center, Johns Hopkins Hospital, Baltimore, Maryland, USA
}

\section{Extract}

Optimal conditions for the in vitro assay of bilirubin uridine diphospho- (UDP) glucuronyltransferase activity in rat liver microsomes are described. Solvent partitioning was used to separate the conjugated from nonconjugated bilirubin, thus avoiding dependency on the rate of coupling with diazotized sulfanilic acid for the distinction between bilirubin and its conjugated form. The inclusion of uridine diphospho- $\mathrm{N}$-acetylglucosamine (UDPNAG) in the reaction mixture permitted the rate of conjugation of bilirubin by fresh rat liver homogenates and microsomes to occur at greater saturation of the available enzyme with the substrates bilirubin and UDP-glucuronic acid. Liver microsomes, isolated in $0.15 \mathrm{M} \mathrm{KCl}$, increased their activity for bilirubin conjugation and decreased their dependency on UDPNAG during the first 10 days of storage at $-15^{\circ}$. Chromatographic separation of the azo pigments of the conjugated bilirubin gave evidence to suggest that bilirubin monoglucuronide was the initial product and bilirubin diglucuronide appeared in increasing amounts in more prolonged incubations. These results suggested that bilirubin monoglucuronide can be intermediate to the formation of bilirubin diglucuronide. Bilirubin UDP-glucuronyltransferase activity in hepatic microsomes of adult homozygous Gunn rats was not demonstrable. In microsomes of heterozygous Gunn rats and normal Wistar and SpragueDawley rats bilirubin UDP-glucuronyltransferase activity was found to be 31.0 and $58.0 \mu \mathrm{g}$ bilirubin conjugated $/ \mathrm{mg}$ microsomal N/30 min, respectively. Measurements in developing rats indicated that the maturation in enzyme activity occurred by at least two distinct means: increase of specific activity of the microsomes, and an increase in the content of microsomes per gram of liver (Table IV).

\section{Speculation}

A method for quantitative measurement of bilirubin UDP-glucuronyltransferase activity applicable to samples obtained by needle biopsy has been needed. The method described in this report meets this need and may permit more precise differential diagnosis of retention jaundice of infancy and childhood and especially the "physiologic" jaundice of the newborn. 


\section{Introduction}

Conjugation of $o$-aminophenol, $p$-nitrophenol, and bilirubin $[9,17,31,32]$ with glucuronic acid by uridine diphospho- (UDP) glucuronate glucuronyltransferase (EC. 2.4.1.17) occurs at different rates. These rate differences are consistent with the existence of either separate transferase enzymes or a single enzyme with different substrate affinities $[1,4,13,14,33]$. Thus, the homozygous jaundiced Gunn rat conjugates $p$-nitrophenol normally but has only a partial capacity to conjugate $o$-aminophenol and is unable to conjugate bilirubin [6, 28, 34]. Consequently, measurements of UDP-glucuronyltransferase activity for bilirubin should employ bilirubin as the substrate in an assay system that is optimal for conjugation of that substrate and permits accurate determination of the conjugated products.

The assay conditions that have been used for the measurement of UDP-glucuronyltransferase activity in rat liver homogenates have not been uniform and the reported activities for normal rats have ranged between 40 and $666 \mu \mathrm{g}$ bilirubin conjugated/g liver/30min incubation $[8,9,17-20,30,35]$.

Diversity of assay results reflects failure to achieve saturation of the enzyme with uridine diphosphoglucuronic acid (UDPGA). The amount of aglycone conjugated was reported to be proportional to the amount of UDPGA available [5]. Pogell and Leloir [23] dem. onstrated that many reagents increased the activity of UDP-glucuronyltrarsferase for conjugation of $p$-nitrophenol and showed that addition of ethylenediaminetetraacetate (EDTA), certain nucleoticles, particularly uridine diphospho- $N$-acetylglucosamine (UDPNAG), and the detergent, digitonin, increased the conjugation of the aglycone. Others have extended these observations $[2,9,10,12,35,37]$.

Many measurements of conjugated bilirubin have depended on the property of conjugated bilirubin to form hydroxypyrromethene azo derivatives with $p$-diazobenzene sulfonic acid in the absence of alcohol or other accelerators ("direct reacting" fraction). The direct reacting bilirubin, unfortunately, cannot always be equated quantitatively to bilirubin glucuronide. The determination is performed in the presence of nonconjugated bilirubin in media of high ionic strength and variable amounts of protein, solubilizers, and detergents. All of these conditions permit nonconjugated bilirubin to react with the diazo reagent [16]. High blank values have been reported $[17,30]$, and the limitations of this method in the determination of bilirubin glucuronicle by direct analysis of liver homogenates have been reviewed [3]: Investigators [11, 15] attempting to avoid these limitations have used the reaction with diazotized sulfanilic acid followed by extraction of the formed azo pigments and separation of the conjugated from the nonconjugated azo pigment by column chromatography. This method is time-consuming and difficult to quantitate. The substitution of diazotized ethyl anthranilate in place of sulfanilic acid has been reported to be more selective for the measurement of conjugated bilirubin in the presence of nonconjugated bilirubin [35]. The technique of isolating conjugated from nonconjugated bilirubin by the solvent system of Weber and Schalm [36] is a useful modification that was employed by Halac and Reff [9] and Nenken, Barrett, and Berlin [18]. In this method the polar conjugates of bilirubin are separated from nonconjugated bilirubin before the reaction with diazotized sulfanilic acid is performed.

The present study describes an improved assay system for the determination of UDP-glucuronyltransferase activity in rat livers. The isolation and characterization of the conjugated bilirubin were done by solvent extraction and thin layer chromatography of the polar conjugates in the form of their hydroxypyrromethene azo derivates. On the basis of conjugating ability the assay could distinguish liver samples from normal Wistar rats and heterozygous and homozygous Gunn rats.

\section{Materials und Methods}

\section{Incubation Mixture}

The components listed in Table I were placed in a 10-ml Erlenmeyer flask chilled on ice. All solutions containing bilirubin were handled in subdued light. Incubations were done at $37^{\circ}$ for timed intervals in a Dubnoff shaking incubator at $90 \mathrm{cycles} / \mathrm{min}$ and the enzymatic reaction was stopped by placing the flasks in an ice bath. The conjugated bilirubin was measured within $30 \mathrm{~min}$ after completion of the incubation.

The proportionality of bilirubin conjugation to the amount of enzyme was verified by inclusion of different amounts of enzyme preparation.

A bilirubin-albumin solution (1.5:1 м concentration ratio) was made by mixing separately prepared solutions of $625 \mathrm{mg}$ bovine crystalline albumin [38] in 0.1 м Tris buffer, $\mathrm{pH} 7.6$, and $7.5 \mathrm{mg}$ crystalline bilirubin [39] in $0.3 \mathrm{ml} 0.25 \mathrm{~m} \mathrm{NaOH}$. The final volume was adjusted to $25 \mathrm{ml}$ with $0.1 \mathrm{~m}$ Tris. Such solutions 
Table I. Composition of incubation mixture for assay of UDP-glucuronyl transferase activity

\begin{tabular}{|c|c|c|c|c|c|c|c|c|}
\hline & Tris, plI 7.6 & Bilirubin & UDPGA ${ }^{1}$ & UDPNAG ${ }^{1}$ & $\mathrm{KCl}$ & $\mathrm{MgCl}_{2}$ & $\begin{array}{c}\text { Enzyme } \\
\text { preparation }\end{array}$ & Total volume \\
\hline Stock solution & $1.0 \mathrm{~m}$ & $0.512 \mathrm{~mm}$ & $33.5 \mathrm{~mm}$ & $33.5 \mathrm{~mm}$ & $1.62 \mathrm{M}$ & $50 \mathrm{~mm}$ & $25 \%$ & \\
\hline Amount & $0.120 \mathrm{ml}$ & $0.200 \mathrm{ml}$ & $0.050 \mathrm{ml}$ & $0.050 \mathrm{ml}$ & & $0.120 \mathrm{ml}$ & $0.200 \mathrm{ml}$ & $0.74 \mathrm{ml}$ \\
\hline $\begin{array}{l}\text { Final concentra- } \\
\text { tion }\end{array}$ & $189 \mathrm{~mm}^{3}$ & $0.138 \mathrm{~mm}$ & $2.26 \mathrm{~mm}$ & $2.26 \mathrm{~mm}$ & $0.15 \mathrm{M}$ & $8.1 \mathrm{~mm}$ & & \\
\hline
\end{tabular}

1 UDPG $\Lambda$ : Uridine diphosphoglucuronic acid; UDPN $\Lambda$ : uridine diphospho- $N$-acetylglucosamine. UDPG 1 was dissolved in $1.62 \mathrm{~m}$ KCl.

${ }^{2}$ Resuspensions of nicrosomes in $0.15 \mathrm{~m} \mathrm{KCl}$ derived from the $25 \%$, w/v, of liver homogenate.

3 The $162 \mathrm{~mm}$ from the $1 \mathrm{M}$ Tris $+27 \mathrm{~mm}$ from the $0.1 \mathrm{~m}$ Tris-bilirubin-albumin solution.

contained $30 \mathrm{mg} / 100 \mathrm{ml} \pm 0.5$ bilirubin as determined by a micromodification [22] of the method of Malloy and Evelyn, and were stable for 3 weeks if kept at $5^{\circ}$ in the dark.

Uridine diphosphoglucuronic acid [40] and uridine diphospho- $N$-acetylglucosamine [41] were prepared as $33.5 \mathrm{~m}$ r solutions in $1.62 \mathrm{M} \mathrm{KCl}$ on the day of use.

\section{Separation and Determination of the Conjugated Bili- rubin}

After incubation, $0.200-\mathrm{ml}$ aliquots of the reaction mixture were transferred into each of two centrifuge tubes containing $1.3 \mathrm{ml}$ of an ice-cooled mixture of ethyl acetate and lactic acid $(5: 8, \mathrm{v} / \mathrm{v})$ and mixed. Chloroform $(1.6 \mathrm{ml})$ was added and thoroughly dispersed. Diazotized sulfanilic acid $(0.024 \mathrm{ml}(10 \mathrm{ml}$ $0.4 \%$ sulfanilic acid in $0.68 \mathrm{M} \mathrm{HCl}+0.3 \mathrm{ml} 2 \%$ sodium nitrite)) was added to one tube, and an equal volume of $0.68 \mathrm{M} \mathrm{HCl}$ to the other tube which served as a blank. Both tubes were shaken, centrifuged, and allowed to stand at room temperature in the dark for 1 Irr. The extinction of the upper polar layer was measured in $1-\mathrm{ml}$ matched cuvettes with a $1-\mathrm{cm}$ light path at $555 \mathrm{~m} \mu$ against its blank in a Zeiss spectrophotometer, PM QII. Control incubations consisted of addition of components cited in Table $I$ and were either kept on ice, or incubated with heat-inactivated microsomes, or UDPGA was omitted.

The calibration curve for conversion of optical extinction of the hydroxypyrromethene azo derivatives in the polar layer to concentration of bilirubin was established by addition of fresh rat bile of known conjugated bilirubin content [22] to samples of liver homogenates, microsomal suspensions, and serum. The recovery of bilirubin in the upper polar layer was equated with the direct reacting bilirubin of the original rat bile. The absorbence of the azo pigments in the ethyl acetate-lactic acid layer conformed to Beer's law. The conversion of $1 \mu \mathrm{g}$ conjugated bilirubin in the polar layer to its azo pigments has an extinction of 0.061 at $555 \mathrm{~m}_{\mu}$ in a $1-\mathrm{cm}$ light path.

\section{Preparation of Homogenates and Microsomes}

Adult rats which had been maintained in the laboratory for at least 10 days were killed by stunning followed by decapitation and exsanguination. The livers were quickly removed and chilled in an ice bath. Homogenates, $25 \%(\mathrm{w} / \mathrm{v})$, were prepared by addition of $0.15 \mathrm{M} \mathrm{KCl}(3.3 \mathrm{ml} / \mathrm{g}$ liver $)$ to the liver sample and the homogenization was performed in an ice-cooled Potter-Elvehjem homogenizer with a close fitting Teflon pestle. The suspensions were centrifuged at 10,000 $\times g$ for $10 \mathrm{~min}$ and the resulting supernatant fluid, subsequently referred to as homogenate, then was centrifuged at $105,000 \times g$ for $60 \mathrm{~min}$. The microsomes were resuspended in $0.15 \mathrm{M} \mathrm{KCl}$ and diluted to the original volume of liver homogenate. Similar homogenates and microsomal suspensions were prepared with 0.25 m sucrose containing 0.001 м EDTA.

Determination of the nitrogen content in the enzyme preparation was done by a micro-Kjeldahl procedure [29].

\section{Chromatographic Identification of the Nucleotides and Polar Conjugates of Bilirubin}

Nucleotides and their degradation products were separated and identified by thin layer ascending chromatography [12] using $2 \mu \mathrm{l}$ incubation media utilizing the solvent system tert-amyl alcohol-formic acid-water $(3: 2: 1)$ [24]. Detection of uridine and its nucleoticles in ultraviolet light was possible in concentrations which exceeded 0.1 nmole. Uridine diphosphate (UDP) and UDPNAG had the same $R_{F}$ values and could not be distinguished from each other, but uridine, uridine monophosphate (UMP), and UDPGA were clearly separable from one another and from the UDP and UDPNAG.

The azo pigments of the conjugated bilirubin were 
isolated from the aqueous polar layer of the solvent partition system. To prevent hydrolysis of the ester linkage with glucuronic acid, a $\mathrm{pH}$ between 1 and 3 was maintained throughout. The lactic acid content and total volume of the polar solvent layer containing the azo pigments were reduced by successive washing with peroxide-free ether until a floccular purple precipitate appeared. The solvent layer containing this precipitate and remaining dissolved azo pigments was diluted with water and the azo pigments were subsequently transferred into l-butanol by repeated extractions. The pooled butanol fractions were washed several times with $0.001 \mathrm{M} \mathrm{HCl}$ and then evaporated at $40^{\circ}$ to a syrupy residue. By further addition of peroxide-free ether a purple precipitate developed which was recovered by centrifugation. The sediment was resuspended in ether, centrifuged, and allowed to dry and subsequently dissolved in either $1 \mathrm{M}$ acetic acid or 1-butanol and spotted on the thin layer plates. The solvent system ethylmethyl ketone-propionic acid-water $(75: 25: 35, \mathrm{v} / \mathrm{v})$ was used for ascending chromatographic separation of the azo pigments $[26,27]$. The slow moving component $\left(R_{F}, 0.45-0.54\right)$ was characteristic of conjugated azo pigment and the fast moving $\left(R_{F}, 0.63-0.68\right)$ represented free azo pigment.

\section{Animal Sources}

Rats of the Wistar [43] and Sprague-Dawley [44, 45] strains were obtained commercially. The Gunn rats were bred locally to produce homozygous jaundiced and heterozygous anicteric rats by mating homozygous males with heterozygous females. The dropping pans beneath the suspended cages were covered with Sani Chips [46]. The pregnant rats and their young were kept in plastic breeder cages in direct contact with the Sani Chips. A laboratory ration [47] was fed ad libitum.

\section{Results}

\section{Dependency of the Rate of Conjugation of UDPGA Concentration}

Assays of sucrose homogenates and microsomal suspensions in Tris buffer, $\mathrm{pH}$ 7.4-8.0, demonstrated that the rate of conjugation of bilirubin was dependent on the concentration of UDPGA and no evidence of enzyme saturation was reached despite increasing the concentration of UDPGA to $22.6 \mathrm{~mm}$ (Fig. 1). Examination of thin layer cliromatograms for nucleotides at the end of the assays did not reveal any residual

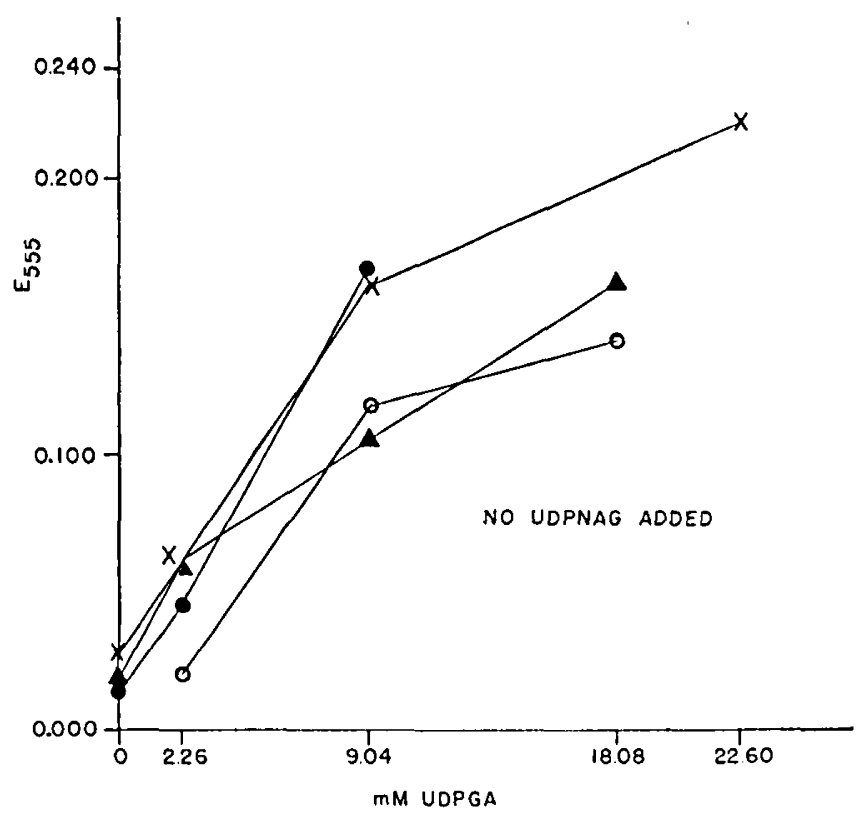

Fig. 1. Relationship of the rate of bilirubin conjugation to UDPGA concentration. The incubation mixtures consisted of $189 \mathrm{~mm}$ Tris $(\mathrm{pH} 8.0$ ), $0.055 \mathrm{~mm}$ equimolar bilirubin-albumin, and $5.7 \mathrm{~mm} \mathrm{MgCl}_{2}$. Liver homogenates were prepared from male Sprague-Dawley rats in $0.25 \mathrm{~m}$ sucrose containing $0.001 \mathrm{~m}$ EDTA. The ordinate represents the amount of conjugated bilirubin formed and the abcissa is the UDPGA concentration. All incubations were performed for $30 \mathrm{~min}$. Each set of symbols represents a separate liver preparation.

UDPGA in the incubation mixtures and uridine was the only demonstrable clegradation product. Similarly timed incubations without added bilirubin also showed clisappearance of UDPGA.

The conjugation rate of bilirubin with transferase preparations isolated in $0.15 \mathrm{M} \mathrm{KCl}$ had a similar dependency on the concentration of UDPGA, even though the rate of conjugation was $10-20 \%$ greater in homogenates and microsomes prepared in $0.15 \mathrm{M} \mathrm{KCl}$ than was found in sucrose.

\section{Influence of UDPNAG on the Concentration Require- ments of UDPGA}

Figure 2 illustrates the effect of UDPNAG on the formation of conjugated bilirubin with varying concentrations of UDPGA. The enhancement of bilirubin conjugation by UDPNAG occurred with liver homogenates as well as microsomal suspensions prepared in either $\mathrm{KCl}$ or sucrose. Transferase assays without UDPNAG formed $58.8 \pm 9.2 \%(N=13)$ of the conjugated bilirubin that was produced in simultaneous assays which included UDPNAG. Thin layer chromato- 


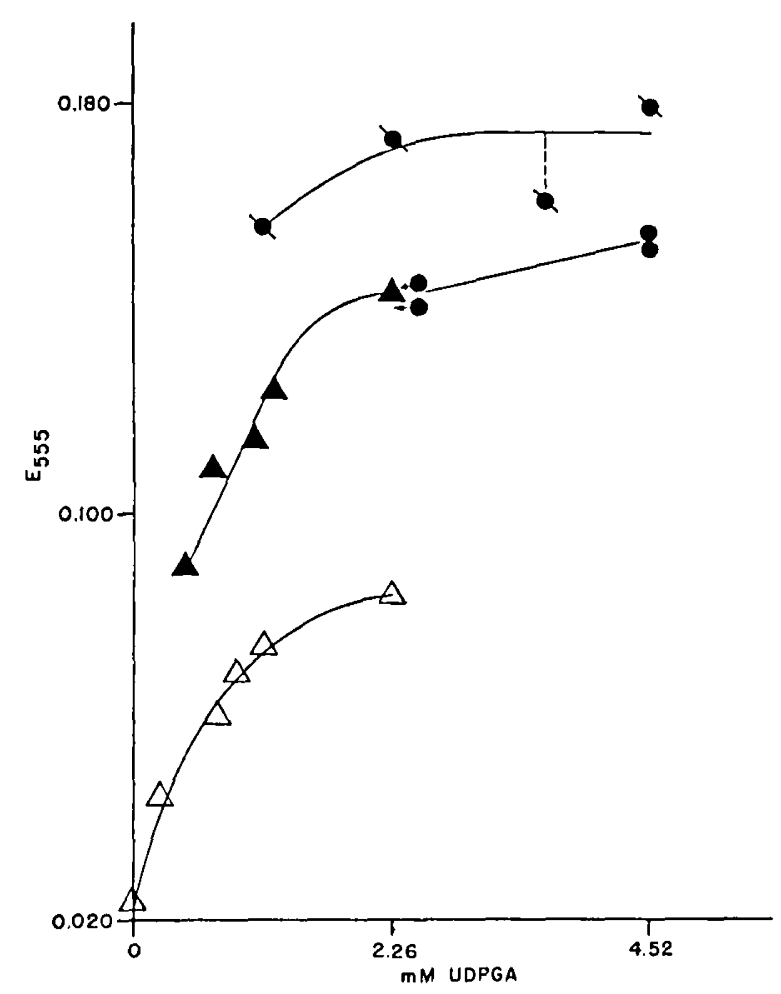

Fig. 2. Relationship of the rate of conjugation of bilirubin to UDPG $A$ concentration with and without UDPNAG. The composition of the incubation mixtures was as described in Table I except for the graded concentrations of UDPGA indicated on the abscissa. All incubations were done for $15 \mathrm{~min}$, in contrast to the 30 -min incubations of Figure 1 . The curves $\Delta$ and $\Delta$ were obtained with the same enzyme preparation, but in the latter incubations the $2.26 \mathrm{~mm}$ UDPNAG was omitted. The symbols - and a represent two additional microsomal preparations which included UDPN $\Lambda$ G.

grams of the incubation mixtures which contained both UDPGA and UDPNAG demonstrated that both nucleotides were still present in substantial amounts after 15 - and $30-\mathrm{min}$ incubations at $37^{\circ}$ and that less uridine had formed. The incubations of microsomal preparations which included UDPNAG but omitted UDPGA showed no formation of conjugated bilirubin. Addition of either UDP, UMP, UDP-glucose, UDP-galactose, adenosine triphosphate (ATP), $N$-acetylglucosamine, glucosamine-HCl, or hydrolyzed UDPNAG in an equimolar concentration to the $2.26 \mathrm{~mm}$ UDPGA did not enhance the conjugation of bilirubin. Figure 3 indicates that the maximum effect of UDPNAG on the conjugation of bilirubin was achieved when $2.26 \mathrm{~mm}$ UDPNAG was used. Inclusion of saccharo-1, 4-1actone [48] to inhibit $\beta$-glucuronidase activity did not result in greater yields of conjugated bilirubin.

\section{Influence of Bilirubin Concentration on Its Glucuro- nide Formation}

Figure 4 illustrates the rate of conjugation of bilirubin at initial concentrations of $0.028,0.055$, and 0.138 mm. Concentrations in excess of $0.138 \mathrm{~mm}$ bilirubin were associated with a slight reduction in its enzymatic conversion. No advantage over the 1.5:1 molar ratio of bilirubin to albumin was observed.

The control incubation flasks which had been kept on ice or did not include UDPGA had extinctions less than 0.025 at $555 \mathrm{~m} \mu$ (Figs. 1 and 2). The control flasks (Fig. 4) had no extinction since they did not contain any bilirubin. The incubations performed with heattreated microsomes and microsomes from homozygous jaundiced Gunn rats also had extinctions less than 0.025 when assayed for bilirubin conjugates.

\section{Influence of $p H$ and Storage on the Conjugation Ac- tivity of Microsomes}

A final concentration of $189 \mathrm{~mm}$ Tris in the incubation mixture maintained a constant $\mathrm{pH}$. The activity

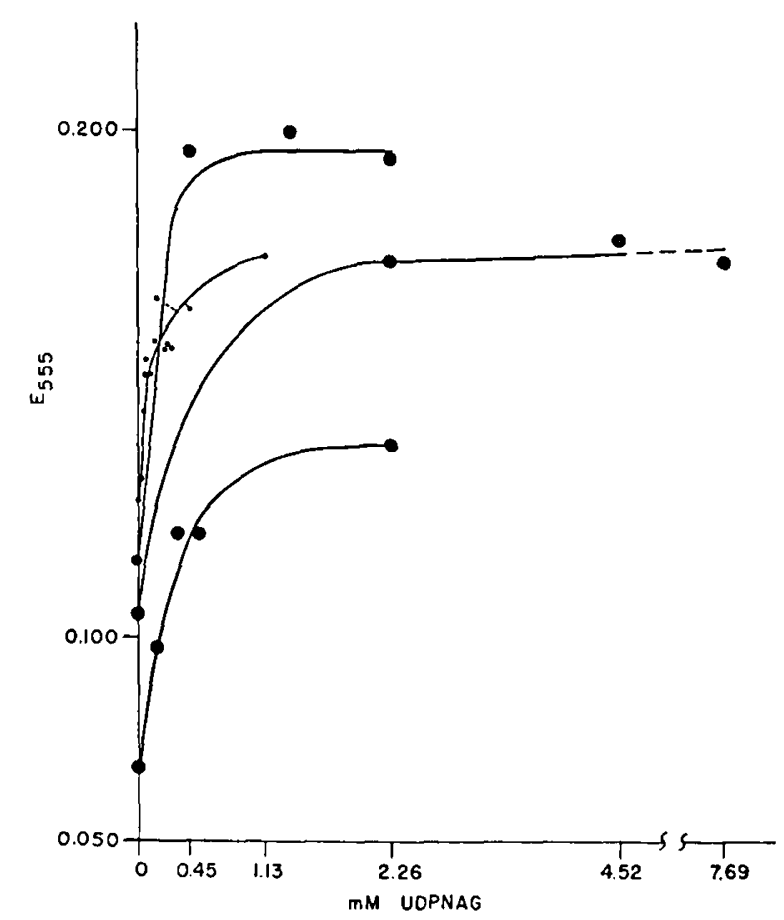

Fig. 3. The influence of UDPNAG on the rate of conjugation of bilirubin. The plotted curves are the values from four separate enzyme preparations. The concentration of UDPGA was 2.26 $\mathrm{mM}$ in all assays, while the UDPNAG was varied in the contration ranges indicated on the abscissa. All other components of the assays were as in Table $I$ and the incubations were done for $15 \mathrm{~min}$. 


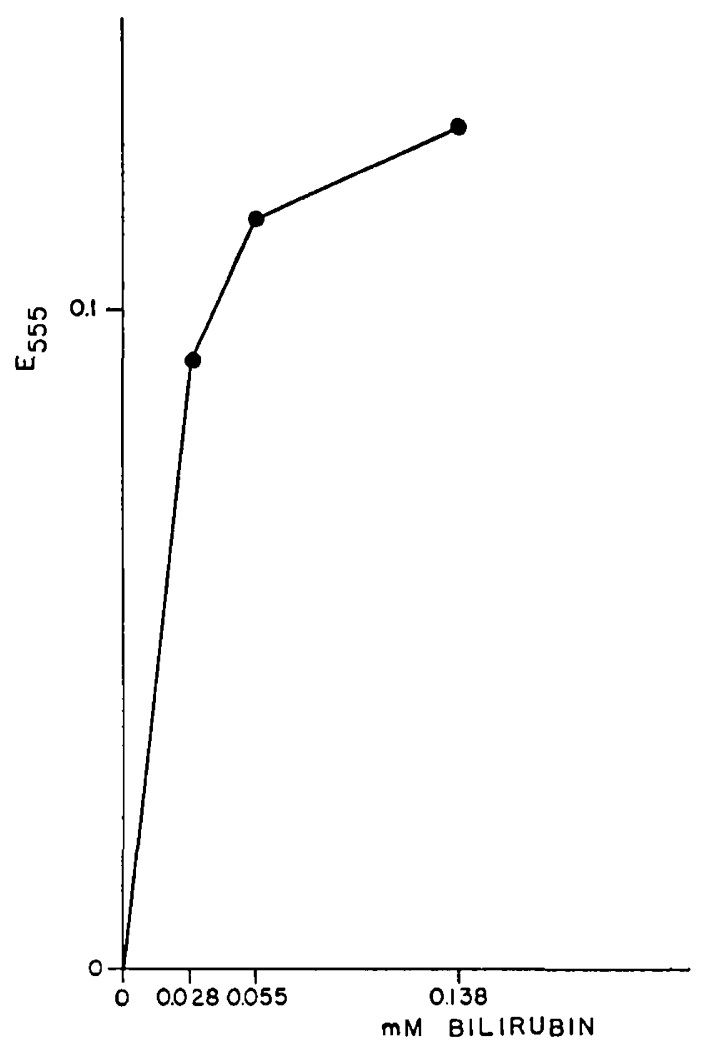

Fig. 1. Relationship of conjugation rate of bilirubin to its initial concentration. The composition of the incubation mixture was as in Table I except for the variation in the amount of bilirubin. The molar ratio of bilirubin to albumin was constant. Incubations were done with the same fresh enzyme preparation for $15 \mathrm{~min}$.

of fresh microsomes and activity of the same microsomes stored at $-15^{\circ}$ for 9 lays at different $\mathrm{pH}$ values is illustrated in Figure 5. The results clemonstrate a $\mathrm{pH}$ optimum between 7.4 and 7.6 at $37^{\circ}$.

Optimal activity for conjugation was found when magnesium was included in the assay system at concentrations between 3 and 15 mm.

The activity of frozen and thawed microsomes exceecled by $48 \pm 16 \%(N=8)$ the activity of fresh preparations after $6-9$ days of storage at $-15^{\circ}$. Figure 6 depicts the typical change in conjugating activity of microsomes associated with storage at $-15^{\circ}$. Simultaneous with the increased activity of the frozen microsomes, dependency on UDPNAG decreased.

Centrifugation of the thawed microsomal suspensions and assay of the sedimentable and supernatant fractions demonstrated that all of the enzyme activity remained in the sedimentable fraction. Microsomes prepared from sucrose homogenates did not exhibit enhanced conjugation of bilirubin after storage at $-15^{\circ}$.

\section{Proportionality of Transferase Activity to Duration of Incubation and Amount of Enzymes}

The formation of bilirubin glucuronide for the first 30 min of incubation (Fig. 7) was linear. In this particular assay about one-fourth of the initial amount of bilirubin was conjugated after $30 \mathrm{~min}$. The curve illustrates a subsequent deviation from linearity for reasons that are suggested from the chromatographic studies on the azo pigment products described below. The amount of bilirubin conjugated was linearly propor-

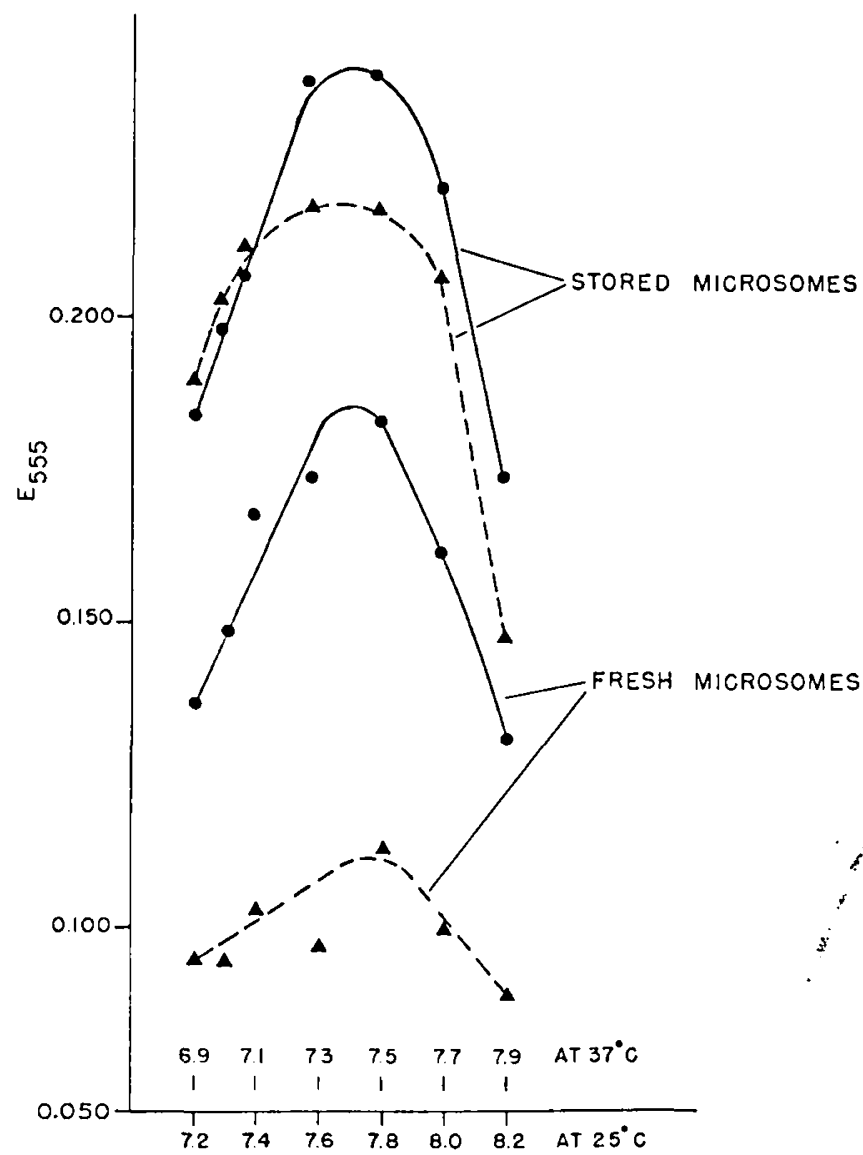

Fig. 5. Influence of pH on UDP-glucuronyltransferase, activity. The $\mathrm{pH}$ of the incubation mixture was varied by addition of $1.0 \mathrm{M}$ Tris buffer of different $\mathrm{pH}$. The $\mathrm{pH}$ was measured (at room temperature) after incubation. The $\mathrm{pH}$ equivalency of Tris buffer at $25^{\circ}$ and $37^{\circ}$ is plotted on the abscissa. The curves $\Delta---\Delta$ represent incubations done without UDPNAG; the curves - refer to incubations which included $2.26 \mathrm{~mm}$ UDPNAG. The two lower curves are results obtained with fresh microsomes; the two upper curves represent the results with the same microsome preparations after storage for 9 days at $-15^{\circ}$. 


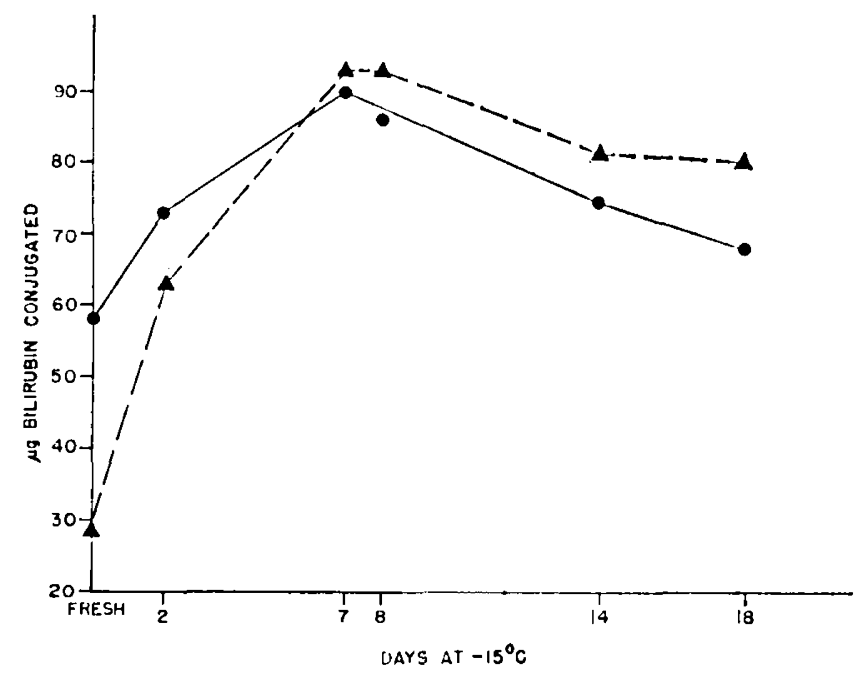

Fig. 6. Effect of storage at $-15^{\circ}$ on UDP-glucuronyltransferase activity of microsomes. The curve $\mathbf{A}^{---} \mathbf{A}$ refers to incubations without UDPNAG, and the curve -1 to incubations which included $2.26 \mathrm{~mm}$ UDPNAG. Each incubation included the same amount of microsomal protein. The ordinate represents in micrograms the amount of bilirubin conjugated $/ 0.5 \mathrm{ml}$ of enzyme preparation/30-min incubation.

tional to the amount of enzyme when $0.02-0.2 \mathrm{ml}$ of the $25 \%$ microsomal suspension was added.

\section{Identification of the Reaction Product}

A flask containing $7.4 \mathrm{ml}$ incubation mixture of the same composition as listed in Table I was incubated for $15 \mathrm{~min}$ simultaneously with two flasks each containing $3.7 \mathrm{ml}$ incubation mixture that had been incubating for 30 and $60 \mathrm{~min}$, respectively. The conjugated bilirubin was recovered from the three incubates by the partitioning, diazo coupling, and isolation procedures described. The quantities of azo pigment which were simultaneously applied to the chromatographic plate did not represent identical fractions of the starting material and were therefore unequal. The pigments isolated from each flask separated into two components. The fast component had an $R_{F}$ characteristic of the azo pigment from crystalline bilirubin, and the $R_{F}$ of the slow component corresponded to the conjugated pigment from fresh rat bile. The spots were eluted in $0.25 \mathrm{ml}$ of a solution of lactic acid (4 vo'umes +1 volume water) and their respective extinctions were measured (Table II). Two additional microsomal preparations from different animals were subsequently incubated for $120 \mathrm{~min}$ and the conjugated bilirubin was treated as described above. The results are given in Table II.

A ratio of 1 between the slow moving and fast mov- ing components was initially observed; higher ratios were found with the longer incubations. Slow moving pigment was converted to fast moving pigment, with an $R_{k}$ similar to that of the nonconjugated azo dipyrrylmethene of crystalline bilirubin, by hydrolysis of the slow pigment in sealed ampoules $(1 \mathrm{~m} \mathrm{HCl}$ for 30 min at $\left.100^{\circ}\right)$. The isolated slow and fast moving azo pigments from rat bile and crystalline bilirubin had identical absorption spectra.

\section{Hepatic UDP-glucuronyllransferase Activity in Liver Tissue of Rats of Different Strains}

The present assay of bilirubin UDP-glucuronyltransferase activity was applied to liver tissue from different strains of rats. The transferase activity was expressed as either bilirubin conjugated by the microsomes from I $\mathrm{g}$ wet weight liver/30-min incubation or as specific activity which is the micrograms of bilirubin conjugated after $30-\mathrm{min}$ incubation per milligram of nitrogen in the microsomal preparation. The incubations were

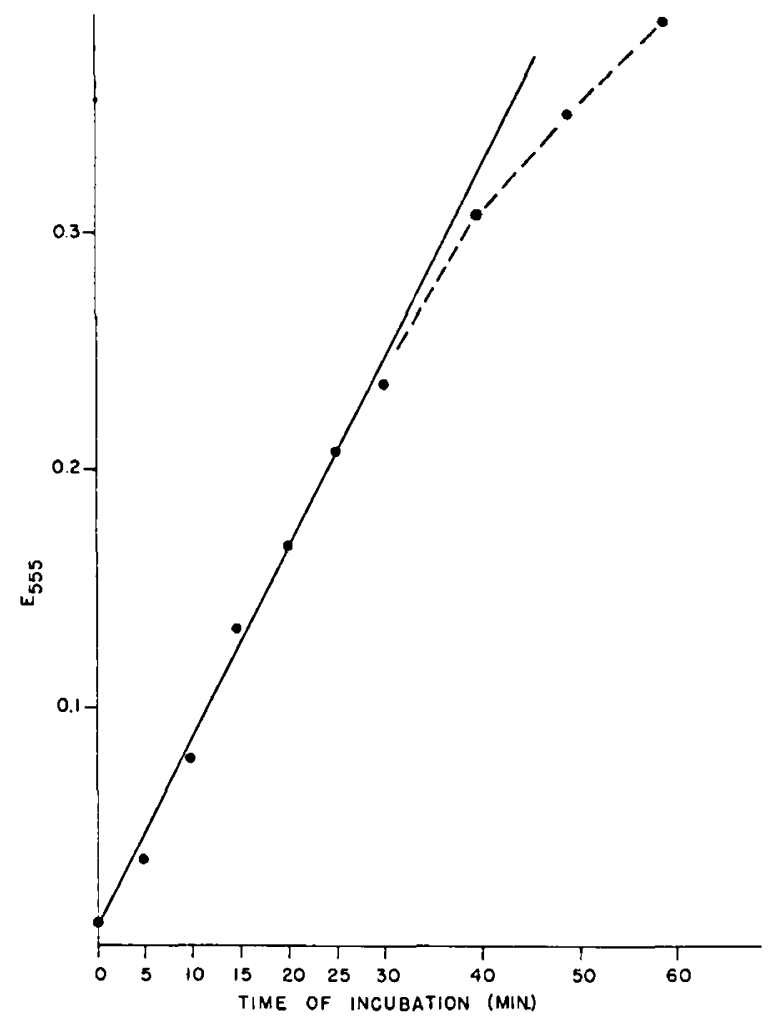

Fig. 7. Relationship of UDP-glucuronyltransferase activity of microsomes to time of incubation. Samples were taken at times $0,5,10,15,20,25,30,40,50$, and $60 \mathrm{~min}$ from the inculbation flask. The substrate concentrations of the melium were as described in Table $I$. The ordinate represents the amount of bilirubin conjugated and the abscissa indicates the duration of incubation. 
done for 15,20 , or $30 \mathrm{~min}$ so that extinctions between 0.1 and 0.25 were obtained. Results have been extrapolated to $30-\mathrm{min}$ incubation intervals (Table III). The transferase activities of the microsomes from Wistar and Sprague-Dawley animals overlap, whereas liver microsomes from heterozygous Gunn rats had significantly lower activities, and no enzyme activity by the present assay was demonstrable in the livers of homozygous Gunn rats.

Maturation of UDP--glucuronyltransferase Activity in Liver Tissue of Heterozygous Gunn and Normal Wis. tar Rats

Pups from the same litter were killed on consecutive days of postnatal life. $A$ rapicl increase of specific activity was observed during the first 4 days of life in both groups of animals and values within the adult range were observed by day 4 . When the results (Table IV; Fig. 8) were expressed as the activity per gram of liver, however, a more gradual increase was noted with age, and adult values had not been reached by the time of weaning. Table IV also inclicates that the nitrogen content of the hepatic microsomes isolated from the suckling animals showed a progressive increase with postnatal age. The microsomal nitrogen of the liver microsomes in the 7 - to 25 -day postnatal animals was signifcantly lower than that observed in adult animals $(P<$ $0.01)$.

In order to detect possible large losses of enzyme protein in the isolation of the microsomes from liver homogenates of suckling animals, transferase assays were performed on the supernatant fluid obtained after centrifugation of the total homogenates at 10,000 $\times g$ for $10 \mathrm{~min}$. Assays were simultancously carried out on microsomes derived from this supernatant fluid in 10 heterozygous Gunn rats (15-25 clays of age). The enzyme activity of $0.5 \mathrm{ml}$ supernatant fluid and microsomal suspensions after 30 -min incubation was $21.9 \pm$ 4.8 and $19.9 \pm 5.7 \mu_{\mathrm{g}}$ bilirubin conjugated by the supernatant fluid and microsomes, respectively. These values were not statistically different. The percentage of enzyme activity in microsomal suspensions from adult liver preparations relative to the supermatant fluid $(10,000 \times g$ for $10 \mathrm{~min})$ was $98.6 \pm 4.1 \%(N=7)$ when the microsomes were isolated in 0.15 ar $\mathrm{KCl}$. With sucrose isolates, the recovery was only $69.2 \pm$ $8.8 \%(N=5)$.

The same proportional increase in transferase activity found in tissue of adult animals in response to addition of UDPNAG was observed in the fresh homogenate and microsomal preparations from sucklings
Table II. Azo pigments derived from in vitro conjugation of bilirubin

\begin{tabular}{cccc}
\hline \multirow{2}{*}{$\begin{array}{c}\text { Azo pigments } \\
\text { from timed } \\
\text { incubations, min }\end{array}$} & \multicolumn{2}{c}{$\begin{array}{c}\text { Extinction at } 555 \mathrm{m \mu} \text { of } \\
\text { eluted azo pigments }\end{array}$} & $\begin{array}{c}\text { Ratio of } \\
\text { extinctions, } \\
\text { slow/fast }\end{array}$ \\
\cline { 2 - 3 } & $\begin{array}{c}\text { Slow moving } \\
\text { pigment }\end{array}$ & $\begin{array}{c}\text { Fast moving } \\
\text { pigment }\end{array}$ & \\
\hline 15 & 0.038 & 0.033 & 1.15 \\
30 & 0.032 & 0.026 & 1.23 \\
60 & 0.050 & 0.020 & 2.50 \\
120 & 0.393 & 0.173 & 2.27 \\
120 & 0.295 & 0.130 & 2.27 \\
\hline
\end{tabular}

Table III. Microsomal UDP-glucuronyltransferase activity in liver from rats of different strains

\begin{tabular}{|c|c|c|c|}
\hline Species & $\begin{array}{l}\text { Specific activity, } \\
\text { mean } \pm \mathrm{sD}^{1}\end{array}$ & $\begin{array}{l}\text { Activity/g } \\
\text { liver mean } \\
\mathrm{SD}^{2}\end{array}$ & $\begin{array}{l}\text { No. of } \\
\text { animals }\end{array}$ \\
\hline \multicolumn{4}{|l|}{ Adult Wistar } \\
\hline Male & $\begin{array}{l}58.0 \pm 10.3 \\
(6.20 \pm 0.49)^{3}\end{array}$ & $357 \pm 68$ & 18 \\
\hline Female & $\begin{array}{c}56.9 \pm 12.7 \\
(5.81 \pm 0.70)\end{array}$ & $324 \pm 63$ & 6 \\
\hline \multicolumn{4}{|l|}{$\begin{array}{c}\text { Adult male Sprague- } \\
\text { Dawley }\end{array}$} \\
\hline Charles River & $\begin{array}{c}51.4 \pm 10.8 \\
(6.52 \pm 0.98)\end{array}$ & $330 \pm 64$ & 12 \\
\hline Madison & $\begin{array}{c}55.8 \pm 2.1 \\
(6.92 \pm 0.43)\end{array}$ & $389 \pm 32$ & 6 \\
\hline \multicolumn{4}{|l|}{$\begin{array}{l}\text { Adult heterozygous } \\
\text { Gunn }\end{array}$} \\
\hline Malc & $\begin{aligned} 31.0 & \pm 2.0 \\
(6.98 & \pm 0.57)\end{aligned}$ & $216 \pm 2$ & 3 \\
\hline Female & $\begin{array}{c}40.5 \pm 8.0 \\
(6.00 \pm 1.00)\end{array}$ & $244 \pm 47$ & 2 \\
\hline \multicolumn{4}{|l|}{$\begin{array}{l}\text { Adult homozygous } \\
\text { Gunn }\end{array}$} \\
\hline Male & 0 & 0 & 3 \\
\hline Female & 0 & 0 & 3 \\
\hline
\end{tabular}

1 Bilirubin, in micrograms, conjugated per milligram of microsomal Kjeldahl nitrogen/30 min.

${ }^{2}$ Bilirubin, in micrograms, conjugated by the microsomal fraction isolated from $1 \mathrm{~g}$ liver $/ 30 \mathrm{~min}$.

${ }^{3}$ Numbers in parentheses are milligrairs of microsomal nitrogen per gram of liver.

of all ages. The storage of the microsomal preparations at $-15^{\circ}$ was also associated with a similar percentage increase in activity. Qualitatively, the response to UDPNAG and freezing and thawing in livers from suckling animals was identical with the response of microsomal preparations from adult livers. No transferase activity in liver homogenates or microsomes of fetal animals of 19-20 days' gestation was observed whether the mother was a heterozygous or homozygous Gunn rat. 
Table IV. Maturation of UDP-glucuronyltransferase of rat liver

\begin{tabular}{|c|c|c|c|c|c|c|c|c|}
\hline & \multicolumn{4}{|c|}{$\begin{array}{l}\text { Specific activity, } \\
\text { mean } \pm \text { SD }\end{array}$} & \multicolumn{4}{|c|}{$\begin{array}{c}\text { Activity/g liver, } \\
\text { mean } \pm \mathrm{SD}\end{array}$} \\
\hline & $\begin{array}{l}\text { IIeterozygous } \\
\text { Gunn rats }\end{array}$ & $x_{4}$ & Wistar rats ${ }^{2}$ & $N$ & $\begin{array}{l}\text { Heterozygous } \\
\text { Gunn rats }\end{array}$ & $N$ & Wistar rats & $v$ \\
\hline Fetus 5 & 0 & 2 & & & 0 & 2 & & \\
\hline 1 day & $\begin{aligned} 15.9 & \pm 2.9 \\
(4.83 & \pm 0.40)^{6}\end{aligned}$ & 3 & $\begin{array}{c}30.0 \pm 5.3 \\
(3.64 \pm 0.92)\end{array}$ & 6 & $75 \pm 10$ & 3 & $105 \pm 13$ & 6 \\
\hline 2 days & $\begin{array}{c}16.0 \pm 2.2 \\
(5.15 \pm 0.17)\end{array}$ & 2 & & & $82 \pm 8$ & 2 & & \\
\hline 3 days & $\begin{array}{l}21.6 \\
(4.09)\end{array}$ & 1 & & & 88 & 1 & & \\
\hline 4 days & $\begin{array}{l}26.1 \pm 1.4 \\
(4.58 \pm 0.19)\end{array}$ & 4 & $\begin{array}{l}49.9 \pm 3.5 \\
(3.88 \pm 0.46)\end{array}$ & 6 & $115 \pm 14$ & 4 & $193 \pm 18$ & 6 \\
\hline 5 days & $\begin{array}{l}33.4 \\
(4.62)\end{array}$ & 1 & & & 155 & 1 & & \\
\hline $7-25$ days & $\begin{array}{c}29.6 \pm 5.4 \\
(5.22 \pm 0.81)\end{array}$ & 14 & $\begin{array}{l}67.6 \pm 4.6 \\
(4.42 \pm 0.54)\end{array}$ & 4 & $150 \pm 37$ & 14 & $298 \pm 35$ & 4 \\
\hline Adult male & $\begin{array}{l}31.0 \pm 2.0 \\
(6.98 \pm 0.57)\end{array}$ & 3 & $\begin{array}{c}58.0 \pm 10.3 \\
(6.20 \pm 0.49)\end{array}$ & 18 & $216 \pm 2$ & 3 & $357 \pm 68$ & 18 \\
\hline
\end{tabular}

${ }^{1}$ Sce legend to Table III.

2 See legend to Table III.

${ }^{3}$ Seven litters were used in the determinations for heterozygous and three litters for the Wistar suckling animals.

- $N:$ Number of animals or animal pools tested.

6 The livers of 12 and 14 fetuses of 19 days gestational age were pooled.

- Numbers in parentheses are milligrams of microsomal nitrogen per gram of liver.

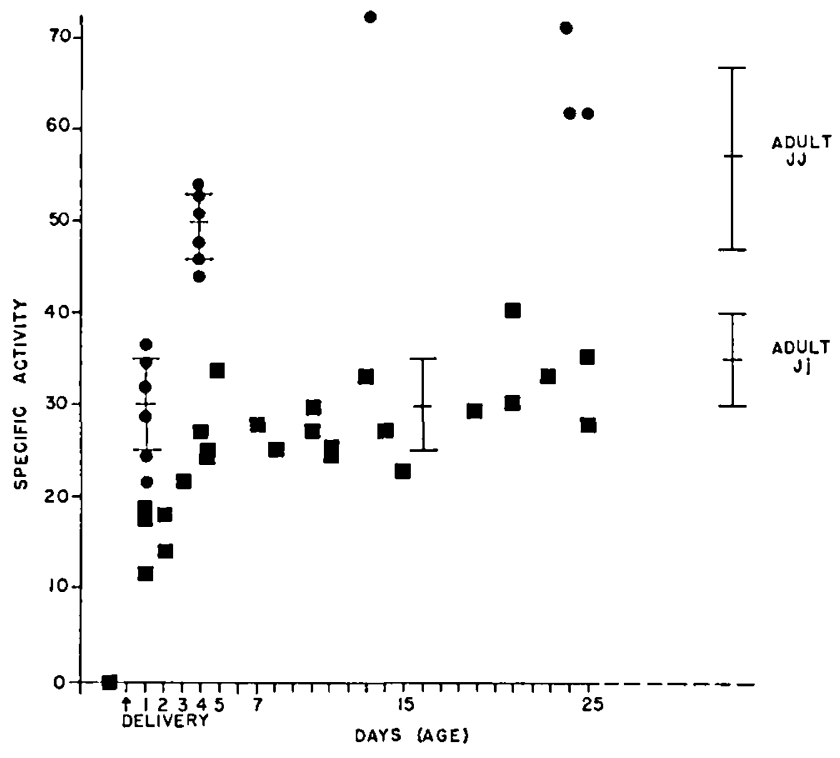

Fig. 8 . Maturation of bilirubin UDP-glucuronyltransferase activity. The conditions for incubation are as indicated in Table $I$. Wistar rats are represented by $\bullet$ and heterozygous Gunn rats by 口. Horizontal bars indicate the means and SD of the micrograms of bilirubin conjugated per milligram of microsomal Kjeldahl nitrogen which is plotted against the age of the animals.

\section{Discussion}

The methods employed demonstrated the presence of competing reactions for UDPGA. When UDPNAG was omitted, UDPGA was rapidly converted to uridine even in the absence of bilirubin conjugation. The relatively low activity of UDP-glucuronyltransferase reported in previous studies $[8,17-19]$ could be explained by the rapid decrease in available UDPGA. This rapid disappearance of UDPGA in liver homogenates and microsomal preparations has been ascribed to the action of either liver pyrophosphatases [23] and/or sugar hydrolases [7].

The inclusion of UDPNAG stabilized the concentration of UDPGA in the reaction media and was associated with enhanced activity of the glucuronyltransferase. This increased activity of microsomal UDP-glucuronyltransferase for conjugation of bilirubin in the presence of UDPNAG is similar to the results of earlier studies [23] where $p$-nitrophenol was used as the glucuronide acceptor. In contrast to that report no enhancement of bilirubin conjugation was obscrved by addition of a number of nucleotides including ATP. The presently observed enhancement by UDPNAG was not found by Winsnes [37] in suspensions of mouse and rat livers when bilirubin was used as substrate but was found with other substrates. This discrepancy may arise from the differences in methodology for the measurement of bilirubin conjugates.

The increased transferase activity of frozen microsomes, when isolated in $\mathrm{KCl}$, and the associated loss of dependency on UDPNAG suggested a selective destruc- 
tion of pyrophosphatase during storage. The frozen preparations, however, exhibited almost $50 \%$ greater transferase activity than fresh preparations which contained optimal concentrations of UDPNAG. The inclusion of UDPNAG, therefore, did not elicit all of the potential transferase activity. Thus, the freezing of the microsomes appears to result not only in the destruction of pyrophosphatase but also in a facilitation of the access of substrates to the enzyme, possibly by greater fragmentation of the microsomes. By freezing and thawing, more enzymic sites on the endoplasmic reticulum were made available to the substrates involved in the transferase reaction. This effect was similar to the activating action reported for digitonin $[2,12]$ and deoxycholate [9]. When liver homogenates or microsomes were treated with these surface-active substances, their activity for the conjugation of bilirubin exceeded the rate reported in the present study in fresh microsomal preparations and they did not require addition of UDPNAG. The conjugation rate of frozen and thawed microsomes was comparable to the detergent-activated preparations.

The isolation of the bilirubin conjugates from the incubation mixtures is based on their greater solubility in the aqueous ethyl acetate-lactic acid mixture than in chloroform. The high ionic strength and low $\mathrm{pH}$ of this partition system would dissociate the unreacted bilirubin from its protein anion ligand, and in the presence of chloroform prevent its retention in the polar layer [21]. The alssence of any significant extinction in the control assays and those performed with microsomes from homozygous Gunn rats attests to the completeness of the separation of conjugated from nonconjugated bilirubin.

The dipyrrylmethene azo derivatives of bilirubin isolated from the polar layer separated into two pigments chromatographically. Their $R_{k^{\prime}}$ values were characteristic of the conjugated and nonconjugated dipyrrylmethene derivatives of bilirubin and they had similar molar extinction coefficients. A ratio of 1 between the extinctions of the fast and slow migrating pigments in the chromatographic separations would suggest that the parent tetrapyrrole was a monoglucuronide, such as was found after 15-min incubation (Table III). The increase in the ratio of the slow to the fast migrating pigments from the polar layer with prolongation of incubation indicates formation of bilirubin diglucuronide, in addition to monoglucuronide, such as was found after 60-min incubation.

The conversion of the isolated slow moving azo dipyrrole by strong acid at high temperature to a product characteristic of nonconjugated azo dipyrrole is compatible with hydrolysis of an acyl glycoside linkage [25].

Since the presently employed solvent-partitioning system extracts both mono- and diglucuronide from the incubates, the apparent rates of conjugation were greater in the shorter incubations because the extracted tetrapyrrole was characteristic of bilirubin monoglucuronicle. The further enzymatic conversion of monoglucuronide to its diglucuronide would not yield proportionately more extractable tetrapyrrole, and a deviation from linearity such as illustrated in Figure 7 would be expected even though the enzyme activity had not decreased.

When the present assay for UDP-glucuronyltransferase activity was applied to liver microsomes from rats of the Gunn strain, it was possible to distinguish genetically determined differences. No overlap in the transferase activities was observed between homozygous and heterozygous Gumn rats and between heterozygous Gunn and normal rats of the Wistar and Sprague-Dawley strains (Table III). Transferase activity in Sprague-Dawley ratts from one commercial source [44] showed greater variation than that in animals from another supplier [45]. This variability may reflect a greater heterogeneity.

The maturation of the glucuronyltransferase was expressed as activity per milligram of microsomal nitrogen (specific activity) and per gram of liver weight of the animal. The specific activity of hepatic microsomes from normal Wistar and heterozygous Gunn rats achieved adult levels by 4 days of age (Table IV). When the values were calculated per gram of liver, however, a more gradual increase in activity with postnatal age was found. These discrepancies can be resolved by considering the increase in specific activity of the microsomes during the first 4 clays of life as maturation. The subsequent increase in enzyme activity per unit of liver weight reflects the accumulation of more microsomes per hepatocyte without change in the protein composition of the endoplasmic reticulum relative to transferase. The accumulation of more microsomal protein per hepatocyte with the same composition with respect to transferase activity might be better considered as simple growth rather than maturation which involves both qualitative and quantitative changes.

\section{Summary}

The in vitro conjugation of bilirubin with glucuronic acid by rat liver microsomes has been demonstrated to be enhanced by inclusion of uridine diphospho- 
(UDP)- $N$-acetylglucosamine. This nucleotide prevented the breakdown of UDP-glucuronic acid. Further enhancement of the conjugating activity of microsomal preparations isolated in $0.15 \mathrm{M} \mathrm{KCl}$ was observed after freezing.

The solvent system of Weber and Schalm was applicd to measure the conjugated bilirubin. The isolation of the azo pigments derived from the conjugated bilirubin and their subsequent chromatographic separation suggested that monoglucuronide may be an intermediate in the production of the diglucuronide.

The assay technique was able to distinguish, on the basis of conjugating activity in liver, homozygous icteric Gunn rats from heterozygous animals and heterozygous Gunn rats from normal Wistar and SpragueDawley rats.

No conjugating activity was found in fetal livers, but by day 4 of postnatal life the specific activity of the microsomal transferase activity was within the range of adult values.

\section{References and Notes}

1. Arias, I. M., Gartner, L. M., Colien, M., Ben Ezzer, J., and LEvI, $A$. J.: Chronic nonhemolytic unconjugated hyperbilirubinemia with glucuronyl transferase deficiency. Clinical, biochemical, pharmacologic and genetic evidence for heterogeneity. Amer. J. Med., 47: 395 (1969).

2. Br.ACK, M., AND BILling, B.: Hepatic bilirubin UDP-glucuronyl transferase activity in liver disease and Gilbert's syndrome. New Engl. J. Mcd., 280: 1266 (1969).

3. Boerti, R. C., BLATt, A. H., ANd Spratt, J. L.: Limitations in the determination of in vitro bilirubin glucuronide formation. J. Lab. Clin. Mcd., 65: 474 (1965).

4. Cillds, B., Sinnury, J. I3., ANI Migeon, C. J.: Glucuronic acid conjugation by patients with familial nonhemolytic jaundice and their relatives. Pediatrics, 23: 903 (1959).

5. Dutton, G. J., AND Storey, I. D. E.: Glucuronide-forming enzymes. In: J. P. Colowick and N. O. Kaplan: Methods in Enzymology, Vol. 5, pp. 159-164 (Academic Press, New York, 1962).

6. Gartner, L. M., AND Ariss, I. M.: Pharmacologic and genetic determinants of disordered bilirubin transport and metabolism in the liver. Ann. N. Y. Acad. Sci., 151: 833 (1968).

7. Glaser, L., Melo, A., and Paul, R.: Uridine diphosphate sugar hydrolasc. Purification of enzyme and protein inhibitor. J. Biol. Chem., 242: 1944 (1967).

8. Grodsky, G. M., and Carbone, J. V.: The synthesis of bilirubin glucuronide by tissuc homogenates. J. Biol. Chem., 226: 449 (1957).

9. Halac, E., and RefF, $\Lambda$.: Studics on bilirubin UDP-glucuronyl transferase. Biochim. Biophys. Acta, 139: 328 (1967).

10. Hatac, E., and Sicignano, C.: Re-evaluation of the influence of sex, age, pregnancy and phenobarbital on the activity of UDP-glucuronyl transferase in rat liver. J. Lab. Clin. Med., 73: 677 (1969).

11. Harbison, R. B., Bofrtil, R, C., ANd Spratt, J. L.: Quantita- tive determination of free and conjugated bilirubin by diazo coupling and a liquid-extraction and column-chromatographic technique. Biochem. J., 104: 46C (1967).

12. Heiriwegi, K. P. M., ANd Meuwissen, J. A. T. P.: Activation in vitro and solubilization of glucuronyl transferase (assayed with bilirubin as acceptor) with digitonin. Biochem. J., 110: $31 \mathrm{P}(1968)$.

13. Issen Bacher, K. J.: Evidence for the multiplicity of glucuronyl transferases. In: K. Beck: Ikterus, pp. 11-15 (Schattauer Verlag, Stuttgart, 1968).

14. Isselbacier, K. J., Chrabas, M. F., and Quinn, R. C.: The solubilization and partial purification of a glucuronyl transferase from rabbit liver microsomes. J. Biol. Chem., 237: 3033 (1962).

15. Lage, G. L., AND SPRatT, J. L.: Bilirubin conjugation by hepatic microsomes from adult male guinea pigs. Arch. Biochem. Biophys., 126: 175 (1968).

16. Latie, G. H., and Ruthven, C. R. J.: Factors affecting the rate of coupling of bilirubin and conjugated bilirubin in the Van den Bergh reaction. J. Clin. Pathol., 11: 155 (1958).

17. Lathe, G. H., and Walker, M.: The synthesis of bilirubin glucuronide in animal and human liver. Biochem. J., 70: 705 (1958).

18. Menken, M., Barrett, P. V. D., and Berlin, N. I.: Assay of hepatic glucuronyl transferase activity using ${ }^{14} \mathrm{C}$ bilirubin as substrate. Clin. Chim. Acta, 14: 777 (1966).

19. Metge, W. R., Owen, C. A., Foulk, W. T., and Hoffman, H. N.: Bilirubin glucuronyl transferase activity in liver disease. J. Lab. Clin. Med., 64: 89 (1964).

20. Metge, W. R., Owen, C. A., Foulk, W. T., and Hoffman, H. N.: Micromethod for estimation of bilirubin glucuronyl transferase activity in needle biopsies of liver. J. Lab. Clin. Med., 64: 335 (1964).

21. Opfl.t, G. B.: The distribution of bilirubin between albumin and mitochondria. J. Pediat., 68: 164 (1966).

22. Odell, G. B., Natzschia, J. G., and Storey, B.: Bilirubin nephropathy in the Gunn strain of rat. Amer. J. Physiol., 212: 931 (1967).

23. Pogell, B. M., AND Leloir, L. F.: Nucleotide activation of liver microsomal glucuronidation. J. Biol. Chem., 236: 293 (1961).

24. RANDERATH, K.: A comparison between thin-layer chromatography and paper chromatography of nucleic acid derivatives. Biochem. Biophys. Res. Commun., 6: 452 (1961-1962).

25. Scinciiter, D.: Nature of the glucuronide in direct reacting bilirubin. Science, 126: 507 (1957).

26. Scrimid, R.: Dircct-reacting bilirubin, bilirubin glucuronide, in serum, bile and urine. Science, 124: 76 (1956).

27. Schmid, R.: The identification of "direct reacting" bilirubin as bilirubin glucuronide. J. Biol. Chem., 229: 881 (1957).

28. Scimmi, R., Axelrod, J., Hammaker, L., and Swarm, R. L.: Congenital jaundice in rats, due to a defect in glucuronide formation. J. Clin. Invest., 37: 1123 (1958).

29. Sfligson, D., And Seligson, H.: A microdiffusion method for the determination of nitrogen liberated as ammonia. J. Lab. Clin. Med., 38: 324 (1951).

30. Shibata, H., Mizuta, M., and Combes, B.: Hepatic glucuronyl transferase activity and bilirubin $T_{m}$ in pregnancy in the rat. Amcr. J. Physiol., 211: 967 (1966).

31. Storey, I. D. E.: Some differences in the conjugation of $o$-aminophenol and $p$-nitrophenol by the uridine diphosphate 
transglucuronylase of mouse-liver homogenates. Biochem. J., 95: 209 (1965).

32. Temple, A. R., Clement, M. S., and Done, A. K.: Studies of glucuronidation. IV. Evidence of different processes for $o$-aminophenol and p-nitrophenol. Proc. Soc. Exp. Biol. Med., 12s: 307 (1968).

33. Tombinson, G. A., AND Yaffe, S. J.: The formation of bilirubin and $p$-nitrophenol by rabbit liver. Biochem. J., 99: 507 (1966).

34. Van Leusden, H. A. I. M., Bakkeren, J. A. J. M., Zilliken, F., AND STolte, L. A. M.: $p$-Nitrophenylglucuronide formation by homozygous adult Gunn rats. Biochem. Biophys. Res. Commun., 7: 67 (1962).

35. VAN Roy, F. P., AND HeIRwegh, K. P. M.: Determination of bilirubin glucuronide and assay of glucuronyl transferase with bilirubin as acceptor. Biochem. J., 107: 507 (1968).

36. WebER, A. P., AND SCHALM, L.: Quantitative scparation and determination of bilirubin and conjugated bilirubin in hu. man scrum. Clin. Chim. Acta, 7: 805 (1962).

37. WiNSNES, A.: Studies on the activation in vitro of glucuronyl transferase. Biochim. Biophys. Acta, 191: 279 (1969).
38. Pentex Biochemicals, Miles Laboratories, Inc., Elkhart, Ind.

39. Pfanstiehl Laboratorics, Waukegan, Ill.

40. Lots 27B-7660, 2713-7670, 12713-7580, Sigma Chemical Company, St. Louis, Mo.; anhydrous ammonium salt.

41. Lot 37B-7120, Sigma; disodium salt.

42. Cellulose MN 300; Macherey, Nagel and Company, Düren, Germany; $250-\mu \mathrm{m}$ thickness.

43. Huntingdon Farms, West Conshohocken, Penna.

44. Charles River Breeding Laboratories, Wilmington, Mass.

45. Spraguc-Dawley Company, Madison, Wisc.

46. Chesapeake Feed Company, Beltsville, Md.

47. Teklad, Winfield, Iowa.

48. Calbiochem, Los Angeles, Calif.

49. The results were presented in part before the Society for Pediatric Rescarch, May 3, 1969, Atlantic City, N. J.

50. Supported by Public Health Service Research Grant nos. HD-02268 and HD-0009l.

51. Requests for reprints should be addressed to: Gerard B. OdfLL, Department of Pediatrics, Johns Hopkins Hospital, 601 North Broadway, Baltimore, Md. 21205 (USA).

52. Accepted for publication December 7, 1970. 